\title{
Política nacional de educação especial na perspectiva da educação inclusiva: por uma (auto)crítica propositiva
}

\author{
National policy of special education in the inclusive education \\ perspective: for a propositive (self) criticism
}

\section{Política nacional de educación especial en la perspectiva de la educación inclusiva: para una (auto)crítica propositiva}

\section{Giovani Ferreira Bezerra ${ }^{1}$}

Universidade Federal da Grande Dourados, Faculdade de Educação, Professor. https://orcid.org/0000-0002-4710-3897

\begin{abstract}
Resumo: Este ensaio aborda a Política Nacional de Educação Especial na Perspectiva da Educação Inclusiva (PNEE-PEI), divulgada em 2008 pelo governo federal brasileiro, com o objetivo de empreender uma crítica ao modo como esta foi implementada nos últimos anos e, também, de apresentar possibilidades para a reformulação dessa política. 0 modelo de Atendimento Educacional Especializado extraclasse é rechaçado, defendendo-se uma proposta de educação inclusiva que incorpore previsão legal de serviços e suportes diversificados para atender as especificidades do Público-Alvo da Educação Especial (PAEE). Discute-se a necessidade de reorganização da escola comum, da formação docente especializada e de participação das escolas especiais em um sistema educacional inclusivo.

Palavras-chave: Política de educação inclusiva. Educação Especial. Atendimento Educacional Especializado.
\end{abstract}

Abstract: This essay deals with the National Policy of Special Education in the Inclusive Education Perspective (PNEE-PEI), released in 2008 by the Brazilian federal government, with the purpose of taking a critique of the way it has been implemented in recent years and also presenting possibilities for the reformulation of this policy. The extraclass Specialized Educational Attendance model is rejected, defending an inclusive education proposal that incorporates legal provision of diversified services and supports to meet the specificities of the Special Education Target Audience (PAEE). The need to reorganize the common school, specialized teacher training and the participation of special schools in an inclusive educational system is discussed.

Keywords: Inclusive education policy. Special education. Specialized Educational Service.

Doutor em Educação, área de concentração em História, Políticas e Gestão da Educação, pela Universidade Federal da Grande Dourados; Mestre em Educação, área de concentração em Educação, Linguagem e Sociedade, pela Universidade Estadual de Mato Grosso do Sul, unidade universitária de Paranaiba. 
Resumen: Este ensayo aborda la Política Nacional de Educación Especial en la Perspectiva de Educación Inclusiva (PNEE-PEI), publicada en 2008 por el gobierno federal brasileño, con el propósito de hacer una crítica de la forma en que se ha implementado en los últimos años y también presentar posibilidades para la reformulación de esta política. El modelo de Asistencia Educativa Especializada extraclase es rechazado, defendiendo una propuesta de educación inclusiva que incorpora la provisión legal de servicios y apoyos diversificados para cumplir con las especificidades de la Audiencia Objetivo de Educación Especial (PAEE). Se discute la necesidad de reorganizar la escuela común, la formación especializada de docentes y la participación de escuelas especiales en un sistema educativo inclusivo. Palabras clave: Política de educación inclusiva. Educación Especial. Servicio Educativo Especializado.

Recebido em 4 de junho de 2020 Aceito em 11 de janeiro de 2021

\section{INTRODUÇÃO}

0 ano de 2018 foi marcado pela vigência de uma década da Política Nacional de Educação Especial na Perspectiva da Educação Inclusiva (PNEE-PEl), divulgada em 2008 pelo governo federal brasileiro. Esses dez anos têm um significado particular, pois representam, justamente, o período em que o ora pesquisador foi se constituindo como interessado pelo campo da Educação Especial, vivenciando, como um de seus agentes, os (e)feitos do discurso hegemônico do momento, as contradições desse mesmo discurso e as tensões que se acumulavam, dia a dia, em torno dessa política, a partir das críticas que chegavam dos demais agentes imbricados no campo: professores e gestores escolares, familiares de pessoas com deficiência, instituições especializadas, pesquisadores da área, dentre outros. Estava posto, assim, o desafio de compreender e construir o próprio sentido de uma educação especial inclusiva, capaz de conciliar igualdade e equidade, o que gerou dissensos e consensos apressados.

Nesse contexto, a própria Educação Especial esteve, de início, subsumida à alardeada novidade da Educação Inclusiva, ainda que uma e outra fossem, conceitualmente, distintas, porém inter-relacionadas, com a última redefinindo o modo de ser da primeira. Nessa década em foco, chegou-se a difundir, contudo - durante algum tempo e em função de compreensões equivocadas -, a ideia de que não se poderia mais falar em Educação Especial, mas somente em Educação Inclusiva, como se esta tivesse "chegado" para substituir aquela, o que certamente criou alguma confusão entre os termos e o apagamento discursivo das especificidades dos estudantes público-alvo da educação especial (PAEE). Uma nova 
correlação de forças foi se impondo, pela qual a escola comum, supostamente convertida em espaço inclusivo, se destacou, de modo imperativo, como o lugar de todos os estudantes, com e sem deficiência, com e sem necessidades específicas de aprendizagem e desenvolvimento humano.

Todas as outras alternativas e serviços estariam, pois, condenados ao desaparecimento e à execração, impondo-se uma interpretação judiciosa que invalidava, $a$ priori, quaisquer outras possibilidades de escolarização desse público. Sintoma das reformas educacionais mundialmente deflagradas a partir da década de 1990 (BEZERRA, 2012), essa lógica radical de tomar a escola comum como novo espaço de (con)formação e captura da diferença inverteu o foco da segregação dos sujeitos para uma incorporação física, no tempo e no espaço, de toda e qualquer alteridade. Dessa forma, tornou mais ágil e eficaz os modos de domínio, possessão e subjugação dessa mesma diferença, sob o que se desenhou, com o advento do século XXl, uma inclusão que aprisiona o outro e cerceia seu vir-a-ser, ao fazê-lo seguir um roteiro pré-estabelecido e despersonalizante. Nas palavras provocativas de Skliar (2003, p. 41),

0 outro da educação foi sempre um outro que devia ser anulado, apagado. Mas as atuais reformas pedagógicas parecem já não suportar o abandono, a distância, o descontrole. E se dirigem à captura maciça do outro para que a escola fique ainda mais satisfeita com a sua missão de possuí-lo, tudo dentro de seu próprio ventre.

Passada mais de uma década da PNEE-PEl, faz-se necessário realizar, portanto, a autocrítica do que se tem dito, pesquisado, praticado e/ou defendido, no intuito de se empreender um balanço das proposições até aqui difundidas e institucionalizadas sobre as proposições da ordem inclusiva no cenário educacional. É sabido que têm sido deflagrados discursos e práticas colonizadores sobre o "outro da educação", imobilizadores de sua própria diferença, seja esta em qualquer sentido. Diante disso, analisar os ((d)e)feitos da PNEE-PEl é o escopo deste ensaio teórico, que, por isso mesmo, toma a liberdade de refletir sobre a experiência brasileira com base nas vivências e concepções de seu autor, de forma a tensionar o tempo presente para perspectivar outro cenário para o campo da Educação Especial em uma orientação inclusiva, mas que supere os reducionismos do ideário inclusivista vigente (BEZERRA, 2012; BEZERRA; ARAUJO, 2013). Como apoio a essas reflexões, incorporam-se aqui as recentes discussões da literatura especializada, comentando-se os pontos da legislação educacional inclusiva brasileira, de modo a criar um panorama descritivo e analítico sobre o tema em questão.

Para tanto, há a preocupação, na primeira parte do exposto, em apresentar criticamente os impactos (ou pactos) dessa política e seus (e)feitos sobre a propalada inclusão 
escolar. Em seguida, vislumbram-se alguns caminhos para se projetar o debate em torno da temática, sem a pretensão de torná-los unívocos, como resultado dessas reflexões, de estudos anteriores e de discussões promovidas durante as aulas ministradas pelo autor e, também, em grupos de estudos e pesquisas dos quais participou ao longo desses anos. Eis a tarefa a que se propõe o presente ensaio, ao realizar, inclusive, uma releitura de alguns posicionamentos anteriores.

\section{A POLÍTICA NACIONAL DE EDUCAÇÃO ESPECIAL NA PERSPECTIUA DA EDUCAÇÃO INCLUSIUA (PNEE - PEI) E SEUS ((D)(E))FEITOS}

A PNEE-PEl veio à luz em 2008, sendo posteriormente normatizada em decretos e resoluções específicas (BRASIL, 2008, 2009b, 2011), haja vista que, como uma política educacional, por si só, não se constituiu em lei, mas em guia de ação, em uma proposição ideológica resultante do embate entre dissensos e consensos, consubstanciada em um acordo, sempre suscetível a novas interpretações, traduções e significações conforme os agentes e as circunstâncias da prática. Daí a necessidade de normatizar pela legislação e fazer valer a vontade vencedora, inclusive com a publicação de diversas notas técnicas pelo Ministério da Educação (MEC) na década considerada (BRASIL, 2016), além de publicações de fascículos institucionais do MEC com orientações para as escolas se tornarem inclusivas e da realização de programas de formação docente. Nesse processo de normatização, a emergência da política significou, de início, um silenciamento tácito de alguns documentos legais, bem como a reinterpretação de outros, para que novos textos e pactos, mais adequados às últimas correlações de forças, pudessem ser produzidos e validados ao sabor do momento.

Sobre isso, há que se lembrar, aqui, a reinterpretação forjada em torno do disposto constitucional, ratificado na Lei de Diretrizes e Bases da Educação Nacional (LDB) 9394/96, sobre o "atendimento educacional especializado aos portadores de deficiência, preferencialmente na rede regular de ensino." (BRASIL, 1988). Esse atendimento, sobretudo no decênio de 2008 a 2018, passou a ser entendido como aquele meramente complementar ou suplementar ao ensino ministrado em classe comum, de modo não substitutivo a esta e em regime de contraturno. Assim, a matrícula de todos os estudantes na escola comum, dita inclusiva, foi entendida como compulsória, cerceando outras formas de escolarização, como aquelas desenvolvidas pelas chamadas escolas especiais, e, ainda, limitando a compreensão dos apoios pedagógicos a serem disponibilizados intraclasse no processo de inclusão escolar. Mesmo as formas complementares e suplementares deveriam estar, de preferência, dispostas na escola comum, que seria a instância mais legitimada para oferta do referido 
Atendimento Educacional Especializado (AEE). Apenas em casos excepcionais, admitir-seia que outros espaços concorressem com a escola comum na oferta especifica de AEE. Não obstante as tensões provocadas, pouco se permitiram a divergência interpretativa e a reflexão sobre o sentido do texto legal no uso deste termo genérico: atendimento educacional especializado. Na análise de Mendes (2019, p. 9),

\begin{abstract}
No tocante ao termo "preferencialmente", constante em toda a legislação e em documentos oficiais da Educação Especial, até então entendida como referência à matrícula em classe comum, foi reinterpretado la partir dos anos 2000] como um advérbio a ser atribuído ao AEE e não mais para a matrícula em classe comum de escolas regulares que passou a ser defendida como compulsória e não preferencial.
\end{abstract}

Com isso, forjou-se a compreensão esdrúxula do AEE como um serviço adicional peculiar a ser ofertado basicamente no contraturno das escolas comuns para os estudantes PAEE, separado no tempo e no espaço em relação às demandas das classes comuns, uma vez que tal serviço foi deslocado, sobretudo, para as Salas de Recursos Multifuncionais (SRM), o que levou à redução desse serviço ao local de sua realização, com a consequente criação de uma figura nova: o professor de AEE, que não mais era identificado como um docente da Educação Especial em sua completude, a respeito de quem logo se falará adiantando-se que se inventou, assim, um professor que era, por definição, prestador de serviços ambiguamente ditos especializados, a partir de determinados recursos materiais e orientações instrucionais que the eram confiados, refém de uma concepção pragmatista sobre o trabalho docente e secundarizado em relação à própria SRM. Ipsis litteris, com os desdobramentos da PNEE-PEl, ficou demarcado que:

As atividades desenvolvidas no atendimento educacional especializado diferenciam-se daquelas realizadas na sala de aula comum, não sendo substitutivas à escolarização. Esse atendimento complementa e/ ou suplementa a formação dos estudantes com vistas à autonomia e independência na escola e fora dela.

Em todas as etapas e modalidades da educação básica, o atendimento educacional especializado é organizado para apoiar o desenvolvimento dos alunos, constituindo oferta obrigatória dos sistemas de ensino e deve ser realizado no turno inverso ao da classe comum, na própria escola ou centro especializado que realize esse serviço educacional. (BRASIL, 2008).

Art. $5^{\circ} 0$ AEE é realizado, prioritariamente, na sala de recursos multifuncionais da própria escola ou em outra escola de ensino regular, no turno inverso da escolarização, não sendo substitutivo às classes comuns, podendo ser realizado, também, em centro de Atendimento Educacional Especializado da rede pública ou de instituições comunitárias, confessionais ou filantrópicas sem fins 
lucrativos, conveniadas com a Secretaria de Educação ou órgão equivalente dos Estados, Distrito Federal ou dos Municipios. (BRASIL, 2009b, p. 2).

Essa foi a resposta política para tornar viável a inclusão escolar, de forma a considerar, em tese, a singularidade do PAEE, sem modificar as estruturas escolares e sua mesmidade, e sem perturbar sua regularidade (não por acaso falamos sempre de escola regular, querendo rechaçar qualquer outro modo de ser da escola e fazendo valer uma determinada norma!). Mais uma vez, a diferença - sempre tão louvada, mas igualmente desconsiderada - era autorizada a se manifestar em um espaço delimitado, próprio, criado para abrigá-la e recebê-la com hora marcada, como em um "consultório de atendimentos", aonde se vai com um "problema" e se espera que, por um serviço individualizado, estruturado em sessões terapêuticas, logo se saia reabilitado. Nos demais contextos, essa mesma diferença do PAEE deveria ser contida e normalizada até se exaurir na classe comum, sob a continuidade de

\footnotetext{
Uma pedagogia que reúne, ao mesmo tempo, a hospitalidade e a hostilidade em relação ao outro. Que anuncia sua generosidade e esconde sua violência de ordem. Uma pedagogia que não se preocupa - e que se aborrece - com a identidade do outro, quando não repete - até a exaustão - somente a ipseidade do "eu". (SKLIAR, 2003, p. 47).
}

Cumpre esclarecer, porém, que, muito mais do que normatizar a realização de AEE no contraturno e torná-lo propriedade de um espaço-tempo particular para governo e acomodação das diferenças apresentadas pelo PAEE, isto é, da SRM (MENDES, 2019), a perspectiva legal de 1988 e de 1996 trazia a mensagem de que se resguardava o direito à educação escolar às pessoas com deficiência; mas, justamente por suas especificidades e demandas, não se fixavam em definitivo o lócus e o tipo, sabendo-se que a escola comum nem sempre poderia ser o melhor espaço para a escolarização desses sujeitos e que se poderia caminhar para uma pluralidade de formas e meios nesse campo. Daí o dispositivo da LDB prescrever que " 0 atendimento educacional será feito em classes, escolas ou serviços especializados, sempre que, em função das condições específicas dos alunos, não for possível a sua integração nas classes comuns de ensino regular." (BRASIL, 1996).

Além disso, lançavam-se as bases de que o ingresso desses alunos na escola comum não poderia se fazer sem oferta concomitante (e não disjuntiva) de apoios intraclasse, os quais deveriam ser incorporados ao espaço-tempo da sala de aula comum. Por conseguinte, esta precisava ser reconfigurada, de modo que se legou daquele momento a seguinte proposição: "Haverá, quando necessário, serviços de apoio especializado, na escola regular, para atender às peculiaridades da clientela de educação especial." (BRASIL, 
1996). É mister enfatizar que a legislação menciona a necessidade de serviços de apoio especializado (no plural), diante da incorporação dos estudantes PAEE na escola comum, sem definir exatamente esses serviços e jamais restringindo-o, como se passou a crer com a PNEE-PEl, ao modelo hegemônico do AEE. Como explica também Mendes (2019, p. 8):

0 que os legisladores sinalizaram com tais termos? Primeiramente, que a matrícula do PAEE em classes comuns de escolas regulares deveria ser priorizada, por esta ser a opção "preferencial", mas, ao mesmo, não precisaria ser necessariamente entendida como compulsória, mesmo porque foi admitida na LDBEN a possibilidade de manutenção da escolarização em classes especiais e escolas especiais, ainda que em caráter extraordinário. A expressão "atendimento educacional especializado", por sua vez, foi - recurso do legislador para dizer que apenas a colocação em classe comum não bastaria e que este alunado iria requerer suporte adicional para responder as suas necessidades diferenciadas.

Destarte, uma das principais críticas a essa política de 2008 foi a redução do conceito de AEE ao mero trabalho realizado nas SRM, de forma divorciada do trabalho desenvolvido na classe comum e pautado em um modelo gerencial de recursos materiais e humanos. Nessa lógica reducionista, entendia-se, sobretudo, que tempo extra para quem apresentasse alguma deficiência ou limitação era, por assim dizer, a solução mais adequada para subsidiar a escolarização desse público, muitas vezes direcionado a uma escola diferente, com colegas diferentes, para receber o tal "atendimento" em contraturno. Com isso, mantiveramse velhas formas - excludentes e ou meramente compensatórias - de a escola e seus agentes se relacionarem com a temporalidade e a espacialidade, limitando a emergência de modelos educacionais inclusivos atentos à diversidade. Tal assertiva fica patente quando se observa que, para fazer valer essa tese do AEE como serviço de contraturno, foi preciso, aliás, condenar ao esquecimento a resolução n. 2/2001 (BRASIL, 2001), não revogada, que trazia ainda o espírito constitucional em sua proposta e não previa um modelo único de suporte ao aluno PAEE. A resolução foi acusada de integracionista e de limitar o ingresso dos estudantes com deficiência à escola comum, bem como de se pautar na lógica de um continuum de serviços que viria na contramão da inclusão total, ao recomendar, inclusive, o encaminhamento excepcional de estudantes para classes e escolas especiais. Realmente, segundo a resolução:

Os alunos que apresentem necessidades educacionais especiais e requeiram atenção individualizada nas atividades da vida autônoma e social, recursos, ajudas e apoios intensos e contínuos, bem como adaptações curriculares tão significativas que a escola comum não consiga prover, podem ser atendidos, em caráter extraordinário, em escolas especiais, públicas ou privadas, atendimento esse complementado, sempre que necessário e de maneira articulada, por serviços das áreas de Saúde, Trabalho e Assistência Social. (BRASIL, 2001, p. 3, grifo nosso). 
Em que pesem as críticas a essa abordagem, construidas, porém, sob o olhar interessado e localizado das formações discursivas tributárias da PNEE-PEl, essa resolução trouxe um entendimento de Educação Especial no sentido da construção de um sistema de educação inclusiva, e não meramente de uma escola inclusiva redentora e redutora, como depois se passou a verificar nos documentos legais, sobretudo a partir de 2008 (BEZERRA, 2012). Desse ponto de vista sistêmico, várias alternativas ficaram em evidência na resolução de 2001, as quais foram sendo negadas ou esquecidas - e mesmo condenadas - ao longo da década de 2008-2018, em nome de uma política uniformizadora (MENDES, 2017, 2019), que, como temos visto, banaliza a própria inclusão escolar por meio de uma

\footnotetext{
[..] concepção poĺtica do serviço de apoio baseado no atendimento educacional especializado extraclasse, como serviço de tamanho único para todos os estudantes. Na prática, este serviço acaba se tornando o lócus de acomodação da diferença na escola, mantendo-se a concepção de que a deficiência está centrada no aluno e que o atendimento vai compensar, provocando pouco ou nenhum impacto na classe comum, numa escola que precisa mudar para oferecer ensino de qualidade para todos. (MENDES, 2019, p. 18).
}

Ao contrário da política de 2008, a lógica de educação inclusiva deflagrada em 2001 - mas logo desmantelada pelo discurso novidadeiro do AEE extraclasse na SRM, que se impôs como o mais legítimo - previa o aluno com ser complexo, alvo de mediações variadas e com "[...] observância do direito de cada aluno de realizar seus projetos de estudo, de trabalho e de inserção na vida social." (BRASIL, 2001, p. 1). Assim, eram reconhecidos, ademais, os limites da escola e classe comuns no tocante à escolarização daqueles que apresentassem necessidades tão intensas, significativas e individualizadas, abrindo-lhes outras possibilidades e percursos formativos, de modo a se assegurar "[...] a busca da identidade própria de cada educando, o reconhecimento e a valorização das suas diferenças e potencialidades, bem como de suas necessidades educacionais especiais no processo de ensino e aprendizagem [...]" (BRASIL, 2001, p. 1). De outro lado, porém, a mesma resolução não negligenciava a pertinência dos apoios na classe comum, em vez de centralizar esforços apenas nos momentos extraclasses, ao explicitar, entre outras estratégias,

||| - flexibilizações e adaptações curriculares que considerem o significado prático e instrumental dos conteúdos básicos, metodologias de ensino e recursos didáticos diferenciados e processos de avaliação adequados ao desenvolvimento dos alunos que apresentam necessidades educacionais especiais, em consonância com o projeto pedagógico da escola, respeitada a frequência obrigatória; 
IV - serviços de apoio pedagógico especializado, realizado, nas classes comuns, mediante: a) atuação colaborativa de professor especializado em educação especial; b) atuação de professores-intérpretes das linguagens e códigos aplicáveis; c) atuação de professores e outros profissionais itinerantes intra e interinstitucionalmente; d) disponibilização de outros apoios necessários à aprendizagem, à locomoção e à comunicação. (BRASIL, 2001, p. 2, grifo nosso).

Com essa previsão legal de serviços e suportes, favorecia-se, ao menos em tese, a educação inclusiva pautada na consultoria e no ensino colaborativos, por exemplo, com foco nas avaliações pedagógicas que evidenciassem as necessidades de cada estudante, independentemente de seu "laudo" ou condição específica, em busca das respostas mais pertinentes a cada caso, sem excluir formas mais individualizadas de atenção docente na classe comum, cada vez mais heterogênea, e "com o cuidado de não gerar discriminação e segregação [...]" (MARIN; BRAUN, 2013, p. 63). Afinal, "um dos grandes desafios da inclusão escolar é justamente favorecer o desenvolvimento específico de um sujeito num contexto coletivo. Para tal, as proposições educacionais apontam a necessidade de individualização do ensino [...]" (MARIN; BRAUN, 2013, p. 54). Por isso mesmo, o ensino colaborativo, depois sequer mencionado na PNEE-PE|, ${ }^{2}$ colocava-se textualmente no horizonte das possibilidades e prescrições legais, visto como

[..] uma alternativa de trabalho que envolve a cooperação entre um professor do ensino comum e um do ensino especial, os quais atuam juntos na mesma classe, quando há a presença de um ou mais alunos com necessidades educacionais especiais que demandam atenção diferenciada. (MARIN; BRAUN, 2013, p. 53).

Todo esse ganho em relação à ideia de adequações curriculares e também de trabalho colaborativo na classe comum, dada sua heterogeneidade, foi perdido e repelido com a PNEE-PEl. Por meio dela, desenhou-se um influxo que homogeneizou o PAEE em categorias estanques, impedindo de se reconhecer a diferença na diferença, isto é, que nem todos os estudantes PAEE se beneficiavam do AEE restrito ao contraturno, sem apoios na classe comum, com a manutenção dos mesmos arranjos escolares e curriculares de sempre. $E$ mais ainda: o PAEE foi essencializado em grupos previamente descritos - deficiência, altas habilidades/superdotação e transtornos globais do desenvolvimento -, o que resultou no

2 A versão preliminar da PNEE-PEl de janeiro de 2008 não trouxe qualquer menção a trabalho docente na perspectiva do ensino colaborativo (Cf. http://portal.mec.gov.br/arquivos/pdf/politicaeducespecial.pdf). A versão publicada, posteriormente, apresentou a lacônica menção a práticas colaborativas, sem desenvolver o conceito, nos seguintes termos: "A educação especial direciona suas ações para o atendimento às especificidades desses estudantes no processo educacional e, no âmbito de uma atuação mais ampla na escola, orienta a organização de redes de apoio, a formação continuada, a identificação de recursos, serviços e o desenvolvimento de práticas colaborativas." (BRASIL, 2008, grifo nosso). 
entendimento - aligeirado - de que para cada grupo de PAEE bastaria lançar mão de um recurso determinado e específico, sem considerar as múltiplas diferenças existentes dentro de cada grupo, entre os próprios grupos e as constantes interfaces produzidas entre eles e todo o contexto circundante. Logo, ao ser proclamada, a diferença foi também cristalizada em uma forma, sem permissão para ser diferente do molde que the fora atribuído! Eis o paradoxo em que caiu a inclusão escolar!

Em tal conjuntura, reforçaram-se estigmas e modos outros de segregação (BEZERRA, 2017), além de se abrir caminho a toda sorte de improvisos, como a contratação de estagiários ou profissionais de apoio sem formação especializada para "auxiliar" lou controlar!) estudantes com deficiência na classe comum (SOUZA et al., 2012; VICENTE; BEZERRA, 2017; BEZERRA, 2020), sem que se avançasse, em termos de política pública, na implementação do ensino colaborativo e na "sustentabilidade do processo inclusivo, mediante aprendizagem cooperativa em sala de aula, trabalho de equipe na escola e constituição de redes de apoio, com a participação da família no processo educativo, bem como de outros agentes e recursos da comunidade." (BRASIL, 2001, p. 2). Sem manifestar grande atenção aos momentos de início e término do processo de escolarização dos estudantes PAEE, a política de 2008 acabou por produzir um perfil de aluno, qual seja, aquele que estava na escola comum como um estudante do ensino fundamental e médio, com necessidades bastante específicas e rotuladas, conhecidas de antemão.

Por isso, no caso das deficiências, parece que eram enxergados somente aqueles alunos com menor comprometimento, ignorando-se os demais casos que, mesmo não sendo tão numericamente expressivos, a despeito das construções discursivas radicais, permaneceram em instituições mais terapêuticas que escolares - as instituições especializadas - ou, então, completamente privados de escolarização e de mediações educacionais. Isso porque, para fins de recebimento de recursos financeiros públicos, houve a indução, pela PNEE-PEl, de transformação de instituições especializadas em Centros de Atendimento Educacional Especializado (CAEE) para ofertar AEE aos estudantes PAEE matriculados em classes comuns, bem como não se superou a predominância da lógica assistencialista e privado-filantrópica nessas instituições especializadas remanescentes, com a falta de respaldo do poder público em relação à organização e ao funcionamento de escolas especiais em sentido estrito.

Ainda nesse sentido, fica patente a pouca atenção manifestada pela PNEE-PEl às crianças da Educação Infantil, as quais até 2009 sequer entravam na faixa de escolaridade obrigatória em nosso país. Foi a Emenda Constitucional $n^{\circ} 59$, de 11 de novembro de 2009 (BRASIL, 2009a) que trouxe essa previsão, depois regulamentada pela Lei n. 12.796, de 4 de abril de 2013 (BRASIL, 2013), ora em vigor. Mesmo assim, só foram contempladas aquelas crianças da pré-escola, a partir dos 4 anos de idade; e as redes públicas de ensino tiveram o prazo de até 2016 para a progressiva implementação dessa normativa. Com isso, não se avançou 
suficientemente na forma de se promover a Educação Especial inclusiva para crianças muito pequenas identificadas como PAEE ou com suspeitas de o serem, para as quais o serviço de estimulação precoce é indispensável e inadiável. Nesses casos, é importante ressaltar que o modelo de AEE restrito à SRM, em contraturno, não beneficia tais crianças, que permanecem, portanto, desassistidas no âmbito dessa política, ineficiente quanto ao atendimento à primeira infância, contrariando a tese de que

\footnotetext{
Nos primeiros anos de vida, devem ser abertas janelas de oportunidades para que a criança aprenda determinados tipos de aprendizagem, que se não forem adquiridas neste período crítico se tornam dificeis, quando não impossiveis, de serem adquiridas mais tarde. Assim, as novas descobertas científicas têm colocado cada vez mais em evidência a importância dos primeiros anos de vida e o papel que o ambiente tem nesse processo, e esse avanço tem implicado uma crescente preocupação social com o cuidado e a Educação Infantil. (MENDES, 2010, p. 48).
}

Assim, mais preocupante tem sido o caso de crianças com menos de 4 anos, cuja escolaridade sequer é obrigatória no Brasil. Muitas delas, pertencentes ao PAEE, estão completamente desassistidas ou dependentes de instituições privado-filantrópicas, que realizam um trabalho nem sempre conectado à perspectiva de educação inclusiva; além disso, reforça-se a lógica da submissão desse público, dependente da filantropia e do favor, quando deveria ter a atenção governamental e o respeito a seus direitos fundamentais, embasados sob a ótica da cidadania e não da benemerência. De fato, quando se entra em qualquer sala de recursos multifuncionais e se observam os materiais enviados pelo MEC, nota-se, certamente, que não se trata de um espaço para crianças pequenas, mas para um aluno de ensino fundamental ou médio, que o utiliza para fins de complementação ou suplementação. Nesse cenário, contudo, como ficam os bebês e as crianças de até 3 anos nas creches do País? Essa ausência é flagrante no modo como se implementou a PNEE-PEl. Sabe-se que a ideia de AEE em contraturno é obviamente impraticável na educação infantil e evidencia a urgência de se falar em serviços de estimulação precoce alinhados à filosofia da educação inclusiva; ao se ignorar essa urgência, essas crianças continuarão cerceadas em suas possibilidades de aprendizagem e desenvolvimento, tornando-se beneficiárias de AEE apenas com o ingresso no ensino fundamental, quando então já se acumulam as deficiências secundárias (VYGOTSKI, 1997).

Essa mesma política também acabou invisibilizando, nos contextos escolares, os estudantes que não se encaixavam no espectro produzido de seu público-alvo, mas que apresentavam dificuldades de aprendizagem, demandando uma resposta da escola, como já recomendara a própria Declaração de Salamanca. A rigor, estudantes com essas 
características também deveriam ter recebido atenção pedagógica especializada, já que a própria política previu, em versão preliminar, posteriormente alterada, que

Na perspectiva da educação inclusiva, a educação especial passa a constituir a proposta pedagógica da escola, definindo como seu públicoalvo os alunos com deficiência, transtornos globais de desenvolvimento e altas habilidades/superdotação. Nestes casos e outros, que implicam em transtornos funcionais específicos, a educação especial atua de forma articulada com o ensino comum, orientando para o atendimento às necessidades educacionais especiais desses alunos.

Dentre os transtornos funcionais específicos estão: dislexia, disortografia, disgrafia, discalculia, transtorno de atenção e hiperatividade, entre outros. (BRASLL, 2008). ${ }^{3}$

0 que se tem verificado, porém, em nome da economia e otimização de recursos, é que esses estudantes com transtornos específicos, mencionados de passagem em texto preliminar da PNEE-PEl e omitidos completamente em suas versões e documentos legais posteriores, não foram considerados pela política de inclusão escolar ou sequer foram alvo de outra proposta nacional que viesse ao encontro de suas demandas. Ao se induzir financiamento do AEE apenas para estudantes com deficiência, transtornos globais do desenvolvimento e altas habilidades/superdotação, os demais estudantes com necessidades específicas de aprendizagem foram relegados a uma espécie de limbo, de modo que a mesma política de educação especial inclusiva acabou por legitimar formas de exclusão e de invisibilidade desses indivíduos, em desacordo com o princípio de Salamanca sobre as escolas inclusivas, segundo o qual:

Muitas crianças experimentam dificuldades de aprendizagem e portanto
possuem necessidades educacionais especiais em algum ponto durante a
sua escolarização. Escolas devem buscar formas de educar tais crianças
bem-sucedidamente, incluindo aquelas que possuam desvantagens
severas. Existe um consenso emergente de que crianças e jovens com
necessidades educacionais especiais devam ser incluídas em arranjos

3 É mister considerar, inclusive, que redação posterior da PNEE-PEl retirou esse trecho, originalmente publicado na versão preliminar de janeiro de 2008, que explicitava, nominalmente, quais eram os transtornos funcionais específicos, bem como promoveu modificações no trecho citado, deixando apenas a menção genérica a transtornos funcionais espećficos, ainda associados, porém, à Educação Especial. Com a mudança, no decorrer do período considerado, o excerto passou a ter a seguinte redação: "Na perspectiva da educação inclusiva, a educação especial passa a integrar a proposta pedagógica da escola regular, promovendo o atendimento aos estudantes com deficiência, transtornos globais do desenvolvimento e altas habilidades/superdotação. Nestes casos e em outros, como os transtornos funcionais espećficicos, a educação especial atua de forma articulada com $\circ$ ensino comum, orientando para $\circ$ atendimento desses estudantes." Comparem-se, dentre outras, as versões disponiveis em: http://portal.mec.gov.br/arquivos/pdf/politicaeducespecial.pdf e http://portal.mec.gov. $\mathrm{br} /$ /index.php?option=com_docman\&view=download\&alias $=16690$-politica-nacional-de-educacao-especial-na-perspectivada-educacao-inclusiva-05122014\&ltemid=30192. 
educacionais feitos para a maioria das crianças. Isto levou ao conceito de escola inclusiva. (UNESCO, 1994).

Por outro lado, os alunos PAEE eleitos pela PNEE-PEl e que recebem o AEE em formato extraclasse não estão em melhor sorte que esses invisibilizados. Sabe-se que os professores especializados, atuantes nas SRM, têm, em grande parte, obtido sua formação "especializada" em nivel de pós-graduação, por meio de especializações bastante questionáveis, realizadas em fins de semana e ou à distância, sem estágios em contextos reais e com diversas fragilidades teórico-metodológicas (HARLOS, 2015). 0 resultado tem sido o agir espontaneísta e cada vez mais esvaziado de competências específicas. No entanto, esse professor multifuncional, destituído do saber-fazer próprio do campo teóricoprático da Educação Especial, foi justamente produzido pela política de 2008, em uma lógica de reconversão docente (GARCIA, 2013). Tal lógica tornou implicitamente questionável e desestimulada a existência de licenciaturas em Educação Especial, delegando a formação inicial do "especialista" dessa área à Pedagogia - já com seus dilemas históricos em torno da formação polivalente - e às demais licenciaturas, o que irrompe na escola como negação do conhecimento sistematizado em Educação Especial e leva à produção de um especialista contraditoriamente generalista, sem condições teórico-metodológicas de exercer seu oficio. Dai ser presa fácil do discurso médico-biologizante e categorizante que retroalimenta, na escola, a deficiência e a (re)produz como diferença temerária, digna de vigilância e conserto, em vez de suportes e apoios.

Ainda é preciso dizer que as instituiç̃̃es especializadas foram alçadas à categoria de inimigas da escola comum e da inclusão escolar, conquanto tenham permanecido, de forma marginal, instituições dessa natureza, mantidas pela iniciativa privada e privado-filantrópica. Ora, há que se pensar que não se discute, no País, sequer o lugar e o papel dessas instituições e das escolas especiais, preferindo o caminho de sua condenação ou suportando-as como mal necessário, mas sem provocar sua incorporação, de fato, ao sistema educacional inclusivo. No máximo, a perspectiva oficial defendeu sua transformação em Centros de Atendimento Educacional Especializado (CAEEs), o que, ademais, se torna temerário, pois essas instituições não só reforçam a dicotomia entre o "comum" e o "especializado" da educação escolar, como também desconsideram que "[...] no sentido de dar acesso ao currículo de base comum para esses estudantes [PAEE] [...], de fato, nem a instituição especializada e nem a escola comum têm conhecimento ou experiência suficiente para tal." (MENDES, 2019, p. 15). Logo, apenas induzir a conversão das instituições especializadas em CAEE não é garantia de oferta aos estudantes com deficiência de um saber-fazer que thes dê apoio na classe comum e que resolva os impasses a que são submetidos diariamente. Tais instituições também precisam se apropriar de práticas educacionais inclusivas e, por isso mesmo, carecem de serem chamadas ao debate. Como ainda defende Mendes (2019, p. 19), 


\begin{abstract}
Em relação às instituições especializadas, cabe destacar, entretanto, que elas precisam se reorganizar enquanto escolas especiais, pois muitas ainda não têm assumido a missão de escolarizar. Ressalta-se, ainda, que a diretriz politica predominante de as transformar em centros de apoio aos alunos da escola pública fomenta a desresponsabilização do setor público, fragilizando a escola pública que perde verbas que poderiam ser aplicadas para ampliar sua missão de contemplar a diversidade de seus alunos e reforça a privatização e filantropia no setor da escolarização de alunos do PAEE. [...]

Assim, a resposta à pergunta sobre $\circ$ que fazer com as instituições especializadas não parece passar nem pela extinção, nem pela reconfiguração delas em centro de apoio e nem pela manutenção delas como hoje funcionam. 0 caminho parece ser a reconfiguração e regulamentação destas instituições para que passem a se organizar e a funcionar, de fato, como escolas especiais para atenderem aos alunos que não se beneficiarão da escolarização em classe comum de escolas regulares.
\end{abstract}

Diante disso, a questão não é meramente reformar a política de 2008 com tintas e termos novos, tampouco impor uma nova por decreto. A questão que se coloca é de fundo e precisa ser encarada em sua radicalidade, sob pena de se manter por mais décadas no impasse de uma escola que se diz inclusiva, mas que (re)produz cotidianamente a exclusão (BEZERRA, 2017). É preciso enfrentar que, nos últimos anos, "As mudanças tem sido, então, quase sempre, a burocratização do outro, sua inclusão curricular e, assim, a sua banalização, seu único dia no calendário, seu folclore, seu detalhado exotismo." (SKLIAR, 2003, p. 40). Isso equivale a dizer que urge superar a mesmidade da escola comum e da PNEE-El de modo a se pensar nas formas de se efetivar o próprio direito à educação escolar dos estudantes PAEE, para além do embate sobre onde fazê-lo. É necessário que se busquem respostas principalmente sobre o como fazer. Afinal,

0 que deve ser assegurado é o acesso ao direito à "educação" e não necessariamente ao "mesmo ambiente dos demais colegas", uma vez que frequentar a mesma escola ou a classe das pessoas sem deficiência não significa essencialmente que $\circ$ direito a educação esteja sendo garantido. (MENDES, 2019, p. 9).

A título de exemplo dessa tese, destaca-se aqui o caso dos estudantes surdos, nem sempre beneficiados com a escola comum dita inclusiva nos moldes em que se encontra, pois nela ingressam, com direito a Tradutor e Intérprete de Língua Brasileira de Sinais (Libras), mas não necessariamente com o pleno domínio da Libras e, muitas vezes, sem pares para dialogar e aprender nessa língua. Nesse sentido, de que valeria um intérprete? Será mesmo que o processo meramente tradutório é adequado para crianças tão pequenas, na educação 
infantil e anos iniciais do ensino fundamentale Certamente é preciso pensar, sim, em escolas e ou classes bilíngues, em que, pelo menos nos momentos iniciais de escolarização, os surdos tenham instrução e interação dialógica em Libras, com acesso ao português escrito como sua segunda língua. Esse tipo de escola até existe - ou existiu - no Brasil, mas foi sendo desestimulado e desencorajado, não ganhando atenção da PNEE-PEl. Este é, talvez, um equívoco a ser enfrentado doravante. Do mesmo modo, alunos com Transtorno do Espectro Autista (TEA), surdocegueira e/ou com deficiência intelectual com severo comprometimento nem sempre terão na sala de aula comum o melhor espaço para aprendizagem e desenvolvimento, demandando recursos e abordagens tão específicas que somente um trabalho individualizado e mais especializado poderá lhes dar condições de avanço e humanização, assegurando a titularidade de seus direitos.

Nesse sentido, com que objetivo se insiste em uma única opção, quando se sabe que há estudantes com necessidades tão específicas as quais, se não forem atendidas, levarão justamente ao resultado oposto apregoado pela inclusão radical, criando novas formas de segregação, preconceito e esquecimento desses alunos? É preciso que se pense no que é essencial e no que é secundário. Entende-se, pois, que essencial é a deflagração do processo educacional, com vistas à humanização de cada ser humano. 0 local onde isso se dará é secundário e será definido em função das demandas apresentadas pelos indivíduos, logicamente com a manutenção, sem negociação, do direito de todos a estar na escola comum, mas sem que se faça desse direito uma obrigação irrenunciável para os sujeitos. A diversidade deve ser não apenas um conceito, mas uma premissa pela qual se organizam os serviços e espaços educacionais, de modo que as múltiplas alteridades possam experienciar a educação escolar como forma, conteúdo e direito subjetivo. No bojo dessas reflexões, avança-se, então, para a segunda parte deste ensaio, com ○ fito de se apresentarem algumas possibilidades para modificar o cenário criticado.

\section{PERSPECTIUAS PARA UMA POLÍTICA OUTRA DE EDUCAÇÃO INCLUSIUA}

Antes de se proporem, no entanto, quaisquer diretrizes para reformulações da política de inclusão escolar, é preciso pôr em debate a própria escola brasileira, tomá-la como objeto de estudo, bem como problematizar as condições de trabalho docente. De fato, a política que foi sendo implementada partiu de uma racionalidade técnica cuja eficácia se revelou limitada. A incorporação dos estudantes PAEE não poderia ser bem-sucedida prevendo-se apenas o serviço de apoio no contraturno, haja vista que, na maior parte do tempo, esses sujeitos estão na classe comum, com professores não especialistas, já envoltos 
com inúmeras cobranças e desafios na realidade do ensino brasileiro. Mantendo-se essa escola da forma como se apresenta, ainda pautada em turnos, aulas rigidamente separadas e AEE extraclasse, com pouca ou nenhuma interação entre professores especializados e professores da classe comum, como acreditar na razoabilidade dessa política de inclusão escolar? Deveria haver um conformismo com a inclusão escolar apenas como ingresso formal do PAEE no sistema comum de ensino? Espera-se que não seja esse o propósito quando se discute a Educação Especial na perspectiva inclusiva.

Por isso, em que pesem as dificuldades materiais para esse empreendimento, sugere-se que se busque a universalização das escolas de tempo integral, mas com professores de educação básica que também sejam de tempo integral a essas escolas - o que favoreceria a criação de vínculos formativos e institucionais com seu local de trabalho. Mas por que uma escola de tempo integral? Ora, esta é uma necessidade do nosso tempo e se constitui na organização mais lógica para que se permita que, num mesmo espaço, sejam incorporados serviços, suportes e profissionais para o trabalho com os estudantes que apresentem necessidades específicas de aprendizagem e desenvolvimento, sejam estes estudantes com ou sem deficiências propriamente ditas. Uma escola de tempo integral, nesses moldes, daria condições laborais para que os professores especializados e os demais docentes atuassem de forma colaborativa, sem se abrir mão, quando estritamente necessário, de formas individualizadas de atendimento, em espaços particulares.

Ao mesmo tempo, essa escola é a única capaz de permitir que, em horário coletivo e conjunto de trabalho, docentes realizem grupos de discussão e estudos de caso de seus alunos, compreendendo as dificuldades e habilidades que eles apresentam, a fim de deflagar a ação pedagógica mais adequada, compondo uma prática autoral. Por meio dessa nova organização didática, mudam-se, também, as relações de espaço-tempo, de maneira que os estudantes podem participar de diferentes configurações e arranjos de ensino, no mesmo local, em uma experiência cotidiana de aprendizagem na e pela diversidade. Certamente não se trata, aqui, apenas de uma escola comum com a jornada escolar ampliada, mas de entender que

Essa nova instituição educativa de tempo integral precisa ser redimensionada e dotar-se de instrumentos que estimulem a criança, o adolescente e o jovem e thes assegure meios de superar todas as suas necessidades. Se a mudança do trabalho didático irá impor os espaços da biblioteca, da sala de multimeios, das salas de computação, das salas de trabalho para pequenos grupos, das salas de professores visando ao atendimento de alunos e à criação de condições adequadas aos seus estudos, a emergente instituição educativa de jornada integral, ao incorporar novas funções sociais, deverá dispor de recursos para atender às necessidades culturais, desportivas, de saúde e de lazer de crianças, adolescentes e jovens. (ALVES, 1998, p. 16). 
Essa escola poderá, ademais, ter como referência de trabalho pedagógico o Desenho Universal aplicado à Aprendizagem (DUA) (PLETSCH; SOUZA; ORLEANS, 2017; ZERBATO; MENDES, 2018), implementando, quando necessário, a elaboração do Plano Educacional Individualizado (PEI) (GLAT; VIANNA; REDIG, 2012), - inovações mais destacadas dos últimos anos no campo de estudos da Educação Especial Inclusiva, sequer mencionadas na versão de 2008 da PNEE-PEl. Enquanto “0 DUA consiste na elaboração de estratégias para acessibilidade de todos, tanto em termos físicos quanto em termos de serviços, produtos e soluções educacionais para que todos possam aprender sem barreiras (ZERBAT0; MENDES, 2018, p. 149-150), o PEl

\footnotetext{
É, em primeira instância, um plano educacional "personalizado", porém inserido no planejamento escolar, ou seja, os conteúdos a serem ensinados coadunam com o que a instituição escolar propõe ao seu alunado em geral. Os professores da turma são responsáveis diretos pelo desenvolvimento do plano, havendo colaboração de outros atores como professores especializados (no caso de alunos incluídos em turmas comuns com suporte), profissionais de outras áreas e até mesmo, da familia. (GLAT; VIANNA; REDIG, 2012, p. 84).
}

Esse instrumento, aliás, torna-se um documento imprescindivel para guiar as ações docentes e fundamentá-las perante as autoridades educacionais, ao mesmo tempo que instiga a superação do imediatismo que se observa nas escolas. Um PEl precisa ser elaborado por determinado período de tempo, periodicamente avaliado, como recurso que medeia a emergência de um trabalho inclusivo, seja para estudantes com déficits de aprendizagens, seja para estudantes imigrantes ou indígenas - com dificuldades na apropriação dos conteúdos por não terem conhecimentos de língua portuguesa -, seja para aqueles temporariamente com problemas de saúde, integrantes de populações nômades, privados da escola, entre tantas outras situações e possibilidades nas quais pode ser acionado. Não obstante, só se pode elaborar um PEl com condições para reflexão, colaboração, análise e acompanhamento a partir dos próprios envolvidos. lsso remete novamente à necessidade de se defender uma escola inclusiva de tempo integral, com dedicação também integral do seu corpo docente, uma vez que 
Uma escola de tempo integral deve ressignificar, ainda, o próprio AEE, que deixará de ser um serviço pontual, no contraturno, para se efetivar no que a própria Constituição e a LDB previam, assegurando apoios diversos na classe comum e nos demais espaços onde estiver o estudante que deles necessitar. Essa escola dará condições para os professores organizarem grupos de estudo a partir de suas necessidades formativas e questões postas pela práxis, sem que se gastem grandes somas de dinheiro com programas de formação continuada na modalidade de pacotões prontos, que pouco dialogam com os docentes e sua práxis. Aos alunos, essa escola propiciará práticas artísticas, momentos de repouso, de envolvimento com a gestão escolar, de trabalho coletivo, mas também de estudo e aprendizagem em pequenos grupos ou em situações personalizadas e customizadas. Como já foi afirmado outrora (BEZERRA, 2012, p. 204, grifo do autor),

\footnotetext{
Desse ângulo, a abertura da escola para alunos com deficiência implica admitir que estratégias diferenciadas e metodologias específicas, pelo menos no ponto de partida, façam parte da ação pedagógica, "L... para que possamos obter uma igualdade de oportunidades efetivas"; em vez de se promover, no que tange a esses estudantes, sua "L...] fictícia aceitação, em suposta condição de igualdade e que é apenas formalmente democrática, mas de fato discriminadora" (SANFELICE, 1989, p. 36). ${ }^{4}$ À luz de tais ponderações, é válido argumentar que a democratização da escola, se quisermos ir além de sua universalização precária, não pode ser entendida de forma dogmática, panfletária e radicalista, no sentido de se impingir a presença compulsória de todos os alunos, em todos os momentos, nas salas de aula comum, com a imposição de uma homogeneidade forçada no ponto de partida. Penso sim que seja de vital importância a defesa de uma escola unitária, em tempo integral, que se oponha à polaridade entre escola especial e escola comum; sala de recursos multifuncionais e sala de aula comum. No mesmo espaço, essa escola unitária pressupõe formas de ensino individualizadas e diferenciadas, mas também não se furta à proposição do estudo coletivo entre todos os estudantes. Seu fundamento é o vinculo orgânico entre a educação especial e a educação geral, como nova síntese superadora.
}

Nesse sentido, cabe debater, também, o papel das escolas especiais, que têm sido vistas como ambientes segregadores. Trata-se de se repensar a organização desses espaços para garantir que o PAEE tenha assegurado, sobretudo, o direito de aprender os conteúdos básicos para seu desenvolvimento e autodeterminação, independentemente do local. As instituições existentes, certamente, não são as que se almejam, dado seu histórico de segregação do alunado "diferente" e de práticas pedagógicas estereotipadas, repetitivas e reforçadoras das deficiências. Por isso mesmo, não se trata de condená-las, mas de viabilizar que estejam disponíveis para aqueles cujas deficiências sejam tão intensas que escola e

4 SANFELICE, J. L. Escola pública e gratuita para todos: inclusive para os "deficientes mentais". Cadernos CEDES, Campinas, $n$. 23, p. 29-37, 1989. Edição Especial. 
classe comuns, mesmo reconfiguradas como antes exposto, se revelem inócuas. É mister traçar uma política nacional que as torne, efetivamente, parte do sistema público de ensino e da oferta de educação especial inclusiva, sem os antagonismos que têm sido observados. Como já se dizia em Salamanca,

Dentro das escolas inclusivas, crianças com necessidades educacionais especiais deveriam receber qualquer suporte extra requerido para assegurar uma educação efetiva. Educação inclusiva é o modo mais eficaz para construção de solidariedade entre crianças com necessidades educacionais especiais e seus colegas. 0 encaminhamento de crianças a escolas especiais ou a classes especiais ou a sessões especiais dentro da escola em caráter permanente deveriam constituir exceções, a ser recomendado somente naqueles casos infrequentes onde fique claramente demonstrado que a educação na classe regular seja incapaz de atender às necessidades educacionais ou sociais da criança ou quando sejam requisitados em nome do bem-estar da criança ou de outras crianças. (UNESCO, 1994).

Destarte, abordar aqui a relevância da escola especial para um contingente pequeno, mas existente, do PAEE não quer dizer voltar ao passado, até porque escolas consideradas especiais nunca deixaram de existir; logo, não são apenas "coisa do passado". Além disso, as instituições especializadas, por tradição, não tiveram como maior preocupação escolarizar seus "assistidos", o que afasta, aliás, a tese saudosista de que, no legado histórico dessas instituições, estariam as respostas para as atuais demandas. 0 que se quer evidenciar é que negá-las como uma alternativa pedagógica equivale a rechaçar outras formas de escolarização existentes para além dos muros da escola comum em sua manifestação hegemônica e que são legitimamente aceitas, como a classe hospitalar, a educação à distância, o atendimento pedagógico domiciliar, ${ }^{5}$ entre outras possibilidades. Dificilmente alguém condenaria tais modalidades de ensino. Por que isso se fez e ainda se faz então com as escolas especiais? Não haveria aí um contrassenso?

Logo, a defesa aqui apresentada dá-se no sentido de chamar tais instituições/ escolas à constituição do sistema educacional inclusivo, sob monitoramento e respaldo do poder público, que deve criá-las, fomentá-las e ou emanar diretrizes para seu funcionamento do ponto de vista escolar, a fim se de (re)construir esse serviço como um dos possíveis para democratizar as oportunidades educacionais de forma equânime para o alunado existente. Posição similar já foi apresentada por Mendes (2019) ao mencionar, sobre o assunto, que "o caminho parece ser a reconfiguração e regulamentação destas instituições para que passem

\footnotetext{
5 Faz-se referência, aqui, aos casos de alunos impossibilitados de frequentar a escola comum por motivos de doença, deficiências graves e ou de impedimentos físicos, temporários ou permanentes, cuja escolarização ocorre no próprio lar, sob responsabilidade de professores vinculados ao sistema público de ensino.
} 
a se organizar e a funcionar, de fato, como escolas especiais para atenderem aos alunos que não se beneficiarão da escolarização em classe comum de escolas regulares." (MENDES, 2019, p. 19). Há uma parcela, mesmo que pequena, de sujeitos os quais demandam formas diversas de acesso ao próprio direito à educação escolar, a quem a escola comum não tem conseguido dar respostas satisfatórias (MENDES, 2019), pois "[...] exigem especificidades de ensino que não são necessariamente compatíveis com a escolarização em classe comum." (MENDES, 2019, p. 17). Por isso mesmo, essas instituições, reconfiguradas, podem vir a ser espaços propícios para programas oficiais de estimulação precoce e de atenção à primeira infância, do ponto de vista de um trabalho educacional inclusivo, entre outras funções a serem redimensionadas, com destaque para a escolarização estrita desse segmento para o qual "[...] o currículo de base comum pouco atende as suas necessidades educacionais, dado que são muito particulares." (MENDES, 2019, p. 17). Ainda como pondera Mendes (2019, p. 19),

\footnotetext{
A opção de usar a expressão "instituição especializada" [...], e não "escola especial", foi intencional, uma vez que chamá-las de escolas seria conferirthes um atributo que a maioria delas ainda não têm. Assim, quando se propõe que tais instituições devam funcionar como escolas especiais propriamente ditas, significa que elas também precisam se reconfigurar para assumir este papel nos sistemas educacionais inclusivos.
}

Para conduzir esse processo, não se pode abdicar de professores com formação especializada. Por isso, insiste-se também na urgência de se promover a articulação de qualquer proposta de inclusão escolar com a iniciativa do poder público em fomentar a abertura e expansão de cursos de licenciatura em Educação Especial, bem como de mestrados profissionais nessa área - no caso destes últimos, como estratégia mais urgente de formação qualificada de quadros profissionais que já possuem uma licenciatura. Como cursos públicos - e presenciais - de licenciatura em Educação Especial, temos apenas dois, em duas regiões distintas do Brasil (OLIVEIRA; MENDES, 2017), isto é, no Sul, na Universidade Federal de Santa Maria, e no Sudeste, na Universidade Federal de São Carlos. Como então se pode pensar no êxito de qualquer política de inclusão escolar quando faltam minimamente agentes com formação para executá-la e/ou fomentá-la? A falta de conexão entre políticas públicas no Brasil aí se reflete, pelo que se evidenciam as dissonâncias entre as políticas de formação docente, de expansão do ensino superior e a política de inclusão escolar. Assim, mediante o exposto,

[...] é importante que os cursos de educação especial se expandam principalmente por IES públicas, ou seja, que o poder público se responsabilize e priorize de fato a formação inicial do professor de educação especial, garantindo a qualidade e excelência em formação de um ensino público superior. Para tanto, é necessário romper com a dicotomia entre formação 
inicial e formação continuada e com a valorização evidente desta em detrimento daquela. (OLIVEIRA; MENDES, 2017, p. 278).

A PNEE-PEl fez, como se sabe, uma opção tácita de investir na formação continuada dos professores para atuarem com o PAEE, haja vista serem necessários apenas conhecimentos pontuais e gerenciais para se tornar um professor de AEE. A propósito, deve-se dar, aqui, a atenção para este termo, hoje muito difundido: professor do AEE. Isso significa, justamente, que se perdeu a referência epistemológica da Educação Especial como campo de formação, com a hegemonia do AEE extraclasse, de modo que cabe ao professor dito especializado apenas organizar o tempo e espaço desse atendimento, sem avançar nos desafios da docência colaborativa, emprestando em seu fazer os esquemas clinicoterapêuticos. Não por acaso a palavra atendimento remete ao trabalho de médicos, psicólogos, fonoaudiólogos, fisioterapeutas e outros da área da saúde. Logo, torna-se urgente pensar em meios de formar o docente da Educação Especial que, muito mais do que um gestor de Sala de Recursos Multifuncionais e prestador de AEE, saiba transitar por diversos serviços e arranjos educacionais inclusivos.

Além disso, é fundamental que os professores especializados já existentes e os que ingressarão nas escolas públicas comuns se tornem servidores públicos de carreira, efetivados por concurso, e não mantidos pelo regime de contrato de trabalho, o que tem sido a tônica em diversos sistemas de ensino pelo Brasil e gerado descontinuidade nas ações escolares inclusivas, com rupturas no desenvolvimento e aprendizagem dos estudantes PAEE. Sem essa garantia mínima de uma carreira e de relativa estabilidade a tais profissionais da Educação Especial, não se viabiliza ter condições necessárias - embora por si sós não suficientes - para a emergência de uma cultura colaborativa e inclusiva nas escolas brasileiras. Bem formar e manter esses professores em regime de dedicação exclusiva a uma escola de tempo integral seria o mínimo esperado para a implementação de uma política educacional condizente com os apelos hodiernos da inclusão escolar, sem recair nos desgastados apelos emocionais.

\section{CONSIDERAÇÕES FINAIS}

No decorrer deste ensaio, argumentou-se que, para se empreender qualquer reformulação da PNEE-PEl, é fundamental lançar mão de uma autocrítica, com enfrentamento da complexidade da educação no Brasil e do próprio PAEE, pois, do contrário, haverá mais desacertos, cujos impactos se propagam por gerações. 0 debate sobre inclusão escolar deve ser pautado nas evidências das diversas pesquisas existentes, bem como incorporar 
as discussões mais recentes sobre planejamento educacional individualizado, desenho universal na aprendizagem, adequações curriculares e reorganização da política de formação e de carreira docentes no País, abrindo-se espaço para uma formação inicial em Educação Especial, bem como outros modos de formação continuada, a qual poderá se dar em mestrados profissionais na área. Não se podem restringir os serviços especializados a um tempo e espaço únicos, mas expandi-los e conectá-los ao direito inalienável de todos à educação formal, seja esta no espaço das escolas comuns, reorganizadas como escolas de tempo integral, seja, extraordinariamente, em escolas especiais, constituindo-se um sistema educacional amplo e inclusivo. Trata-se de buscar, por diferentes meios, a justiça curricular, a remoção de barreiras à aprendizagem e ao empoderamento de cada sujeito, tornando-o cidadão de fato e de direito.

Nesse processo, é preciso entender que a escola comum nem sempre será a melhor alternativa para todos(as) os(as) alunos(as) PAEE, exatamente por ter limitados os recursos especializados que a ela podem ser agregados, dadas as suas configurações institucionais e organizacionais. Isso não significa negar direitos, mas justamente reconhecer a especificidade, em uma política de equidade, condizente com as necessidades e reivindicações dos diversos estudantes com deficiência, altas habilidades e TEA, dentre tantos outros sujeitos, que são constantemente generalizados em suas condições e demandas. É necessário, pois, haver uma política que, sem abrir mão de uma diretriz inclusiva, também não essencialize identidades fixas para seu público-alvo, mas que reconheça que há um espectro em cada deficiência, em cada condição ontogênica. Desse modo, oferecer uma única reposta educativa para todos, em um mesmo espaço torna-se contraproducente, requerendo-se uma lógica epistêmica de educação inclusiva não reducionista, mas que seja atenta à diversidade e que seja diversificada em termos de suportes e serviços. No dizer de Mendes (2019, p. 18),

\footnotetext{
A maioria dos estudantes do PAEE pode e deve estudar nas classes comuns das escolas regulares. Entretanto, uma pequena parcela desta população não se beneficiará do ensino ministrado em tal contexto, dado que precisam de programas alternativos, incluindo currículos muito mais flexíveis que possam acomodar condições sociais, comportamentais, emocionais, cognitivas, de saúde e necessidades de formação profissional do aluno, que são muito peculiares. E se todos os paises ainda mantêm este tipo de provisão, não há razões para o Brasil querer extirpar tais instituiições de sua história.
}

Daí a relevância e urgência de se efetivar uma política nacional de Educação Especial Inclusiva, revisitando-se a Declaração de Salamanca e a já esquecida Resolução n. 02, de 11 de setembro de 2001 (BRASIL, 2001), em vez de se insistir na formalidade da política de inclusão escolar, que toma o aumento de matrículas na classe comum como índice absoluto 
de sucesso, quando se sabe que a realidade evidencia diferentes facetas dessa inclusão, muito mais próximas de práticas excludentes e negativas em relação ao PAEE (BEZERRA, 2017). Certamente, essa proposta requer muito debate e investimento financeiro, humano e político, devendo-se enfrentar posições radicalistas e apaixonadas em torno da defesa de uma escola comum compulsória. Se não se assumir a luta por uma política outra de educação inclusiva, manter-se-á, todavia, a situação de haver estudantes que passam pela escola e são passados por ela, sem que possam se apropriar de conhecimentos que os humanizem e os empoderem para a vida social mais ampla, e sem que essa escola se modifique. 0 objetivo de uma educação inclusiva outra não pode mais ser o de colocar todos no mesmo tempo e espaço, colonizá-los, mas, sim, o de reconhecer que esses tempos e espaços são múltiplos e podem ser intercambiáveis, penetráveis e múltiplos. Essa proposta há de se pautar na “[...] pedagogia do outro que reverbera permanentemente [..." (SKLIAR, 2003, p. 47), isto é, "I...] que contraria as [...] mensagens da pedagogia de outro que deve ser anulado, e que diz [...]: 'não está mal ser o que és', mas também: 'não está mal ser outras coisas além do que já és'." (SKLIAR, 2003, p. 47). Eis o que se espera como ponto de partida para o debate em torno de uma Política Outra de Educação especialmente inclusiva e inclusivamente especial no Brasil, a qual estenda o alcance de suas ações da Educação Infantil ao Ensino Superior, sem polarizações alienantes e politicamente oportunistas.

\section{REFERÊNCIAS}

ALVES, G. L. Nasce uma nova instituição educacional. Intermeio: revista do Mestrado em Educação, Campo Grande, v. 4, n. 8, p. 6-17, 1998. Disponivel em: http://www.desafioonline.ufms.br/index.php/ intm/article/view/2642. Acesso em: 17 set. 2019.

BEZERRA, G. F. A inclusão escolar de alunos com deficiência: uma leitura baseada em Pierre Bourdieu. Revista Brasileira de Educação, Rio de Janeiro, v. 22, n. 69, p. 475-497, abr./jun. 2017. D0l: https://doi. org/10.1590/s1413-24782017226924.

BEZERRA, G. F. A Política Nacional de Educação Especial na Perspectiva da Educação Inclusiva: a problemática do profissional de apoio à inclusão escolar como um de seus efeitos. Revista Brasileira de Educação Especial, Bauru, v. 26, n. 4, p. 673-688, out./dez. 2020. D0l: https://doi.org/10.1590/1980$-54702020 v 26 \mathrm{e} 0184$.

BEZERRA, G. F.; ARAUJO, D. A. de C. Em busca da flor viva: para uma crítica ao ideário inclusivista em educação. Educação \& Sociedade, Campinas, v. 34, n. 123, p. 573-588, abr./jun. 2013. D0l: http://dx.doi. org/10.1590/S0101-73302013000200014.

BEZERRA, G. F. Enquanto não brotam as flores vivas: crítica à pedagogia da inclusão. 2012. $270 \mathrm{f}$. Dissertação (Mestrado em Educação) - Universidade Estadual de Mato Grosso do Sul, Paranaiba, 2012. 
BRASIL. Conselho Nacional de Educação. Câmara de Educação Básica. Resolução n. 2, de 11 de setembro de 2001. Diretrizes Nacionais para a Educação Especial na Educação Básica. Brasília, DF: CNE, 2001. Disponivel em: http://portal.mec.gov.br/cne/arquivos/pdf/CEB0201.pdf. Acesso em: 24 fev. 2010.

BRASIL. Constituição. República Federativa do Brasil de 1988. Brasilia, DF: Senado Federal, 5 out. 1988. Disponivel em: http://www.planalto.gov.br/ccivil_03/constituicao/constituicao.htm. Acesso em: 17 set. 2019.

BRASIL. Decreto $n^{0}$. 7.611, de 17 de novembro de 2011. Dispõe sobre a educação especial, o atendimento educacional especializado e dá outras providências. Diário Oficial da União, Brasília, DF, 18 nov. 2011. Disponivel em: http://www.planalto.gov.br/ccivil_03/_Ato2011-2014/2011/Decreto/D7611.htm\#art8. Acesso em: 24 dez. 2011.

BRASIL. Emenda Constitucional n. 59, de 11 de novembro de 2009. Acrescenta $\S 3^{\circ}$ ao art. 76 do Ato das Disposições Constitucionais Transitórias para reduzir, anualmente, a partir do exercício de 2009, o percentual da Desvinculação das Receitas da União incidente sobre os recursos destinados à manutenção e desenvolvimento do ensino de que trata o art. 212 da Constituição Federal, [...] a inserção neste dispositivo de inciso VI. Diário Oficial da União, Brasília, DF, 12 nov. 2009a. Disponível em: http:// www.planalto.gov.br/ccivil_03/constituicao/emendas/emc/emc 59.htm. Acesso em: 19 fev. 2017.

BRASIL. Lei n. 9.394, de 20 de dezembro de 1996. Estabelece as diretrizes e bases da educação nacional. Diário Oficial da União, Brasilia, DF, 23 dez. 1996. Disponível em: http://www.planalto.gov.br/ ccivil_03/leis/L9394.htm. Acesso em: 6 set. 2011.

BRASIL. Lei n. 12.796, de 4 de abril de 2013. Altera a Lei no 9.394, de 20 de dezembro de 1996, que estabelece as diretrizes e bases da educação nacional, para dispor sobre a formação dos profissionais da educação e dar outras providências. Diário Oficial da União, Brasilia, DF, 5 abr. 2013. Disponível em: http://www.planalto.gov.br/ ccivil_03/_ato2011-2014/2013/lei/l12796.htm. Acesso em: 18 fev. 2017.

BRASIL. Ministério da Educação. A consolidação da inclusão escolar no Brasil (2003-2016). Brasília: MEC, 2016. Disponivel em: http://feapaesp.org.br/material_download/571_Orienta\%C3\%A7\%C3\%B5es\%20 para\%20implementa\%C3\%A7\%C3\%A30\%20da\%20Educa\%C3\%A7\%C3\%A30\%20Especial\%20na\%20Perspectiva\%20da\%20Educa\%C3\%A7\%C3\%A30\%20Inclusiva.pdf. Acesso em: 17 set. 2019.

BRASIL. Ministério da Educação. Conselho Nacional de Educação. Câmara de Educação Básica. Resolução n. ${ }^{\circ} 4$, de $1^{\circ}$ de outubro de 2009. Institui Diretrizes Operacionais para o Atendimento Educacional Especializado na Educação Básica, modalidade Educação Especial. Diário Oficial da União, Brasília, DF, 2 out. 2009b. Disponível em: http://www.cesarcallegari.com.br/v1/edesp.pdf. Acesso em: 21 abr. 2011.

BRASIL. Ministério da Educação. Secretaria de Educação Especial. Política Nacional de Educação Especial na Perspectiva da Educação Inclusiva. Brasília, DF: MEC, jan. 2008. Disponível em: http://portal.mec. gov.br/arquivos/pdf/politicaeducespecial.pdf. Acesso em: 6 out. 2019. 
GARCIA, R. M. C. Política de educação especial na perspectiva inclusiva e a formação docente no Brasil. Revista Brasileira de Educação, Rio de Janeiro, v. 18, n. 52, p. 101-119, jan./mar. 2013. Disponível em: http://www.scielo.br/pdf/rbedu/v18n52/07.pdf. Acesso em: 20 maio 2017.

GLAT, R.; VIANNA, M. M.; REDIG, A. G. Plano Educacional Individualizado: uma estratégia a ser construída no processo de formação docente. Ciências Humanas e Sociais em Revista, Rio de Janeiro: EDUR, v. 34, n. 12, p. 79-100, 2012. Disponivel em: http://www.ufrrj.br/SEER/index.php?journal=chsr\&page=article \&op=view\&path\%5B\%5D=834\&path\%5B\%5D=674. Acesso em: 4 jul. 2014.

HARLOS, F. E. Formação de professores para Educação Especial no Paraná: cursos de pedagogia, pós-graduações lato sensu e políticas públicas. 2015. 165 f. Tese (Doutorado em Educação Especial) - Centro de Educação e Ciências Humanas, Universidade Federal de São Carlos, São Carlos, 2015. Disponivel em: https://repositorio.ufscar.br/bitstream/handle/ufscar/7260/TeseFEH. pdf? sequence=1\&isAllowed=y. Acesso em: 20 maio 2017.

MARIN, M.; BRAUN, P. Ensino colaborativo como prática de inclusão escolar. In: GLAT, R.; PLETSCH, M. Estratégias educacionais diferenciadas para alunos com necessidades especiais. Rio de Janeiro: EdUERJ, 2013. p. 49-64.

MENDES, E. G. A política de educação inclusiva e o futuro das instituições especializadas no Brasil. Arquivos Analíticos de Políticas Educativas, v. 27, n. 22, p. 1-23, 2019. Disponivel em: https://epaa.asu. edu/ojs/article/view/3167/2217. Acesso em: 17 set. 2019.

MENDES, E. G. Sobre alunos "incluidos" ou "da inclusão": reflexões sobre o conceito de inclusão escolar. In: VICTOR, S. L.; VIEIRA, A. B.; OLIVEIRA, I. M. (org.). Educação especial inclusiva: conceituações, medicalização e políticas. Campos dos Goytacazes: Brasil Multicultural, 2017. p. 60-83.

MENDES, E. G. Inclusão marco zero: começando pelas creches. Araraquara: Junqueira\&Marin, 2010.

OLIVEIRA, P. S. de; MENDES, E. G. Análise do projeto pedagógico e da grade curricular dos cursos de licenciatura em educação especial. Educação e Pesquisa, São Paulo, v. 43, n. 1, p. 264-279, mar. 2017. Disponivel em: http://www.scielo.br/pdf/ep/v43n1/1517-9702-ep-S1517-9702201605145723.pdf. Acesso em: 17 set. 2019.

PLETSCH, M.; SOUZA, F.; ORLEANS, L. A diferenciação curricular e o desenho universal na aprendizagem como princípios para a inclusão escolar. Revista Educação e Cultura Contemporânea, Rio de Janeiro, v. 14, n. 35, p. 264-281, 2017. Disponivel em: http://periodicos.estacio.br/index.php/reeduc/article/ view/3114/1662. Acesso em: 21 dez. 2020.

SKLIAR, C. B. A educação e a pergunta pelos Outros: diferença, alteridade, diversidade e os outros "outros". Ponto de Vista: revista de educação e processos inclusivos, Florianópolis, n. 5, p. 37-49, jan. 2003. Disponivel em: https://periodicos.ufsc.br/index.php/pontodevista/article/view/1244. Acesso em: 17 set. 2019. 
SOUZA, A. C. de et al. A inclusão escolar no município de Paranaíba (MS): reflexões sobre a atuação profissional do monitor de alunos com deficiência. Revista Pedagógica, Chapecó: Unochapecó, ano 16, v. 2, n. 29, jul./dez. 2012. Disponivel em: http://bell.unochapeco.edu.br/revistas/index.php/pedagogica/article/view/1467. Acesso em: 10 set. 2015.

UNESCO. Declaração de Salamanca sobre princípios, poĺticas e práticas na área das necessidades educativas especiais e estrutura de ação em educação especial. Salamanca: Unesco, 1994. Disponível em: http://portal.mec.gov.br/seesp/arquivos/pdf/salamanca.pdf. Acesso em: 2 dez. 2011.

VICENTE, B. T.; BEZERRA, G. F. Estagiários e professores regentes como agentes do processo de inclusão escolar: problematizando suas linterlações. Revista Linhas, Florianópolis, v. 18, n. 38 , 214-244, set./dez. 2017. Disponivel em: http://www.revistas.udesc.br/index.php/linhas/article/ view/1984723818382017214/pdf. Acesso em: 12 fev. 2020.

VYGOTSKI, L. S. Obras escogidas V: fundamentos de defectología. Madrid: Visor, 1997.

ZERBATO, A. P.; MENDES, E. G. Desenho universal para a aprendizagem como estratégia de inclusão escolar. Educação Unisinos, São Leopoldo, v. 22, n. 2, p. 147-155, abr./jun. 2018. Disponível em: http:// revistas.unisinos.br/index.php/educacao/article/view/edu.2018.222.04/60746207. Acesso em: 17 set. 2019.

Endereço para correspondência: Rua João Rosa Góes, 1761, Vila Progresso, 79825-070, Dourados, Mato Grosso do Sul, Brasil; gfbezerra@gmail.com 